\title{
Effective Approaches for Teaching STEM-literacy for All Majors: The Ex- ample of Resonance
}

\section{Dr. Maria E. Garlock, Princeton University}

Maria Garlock is an Associate Professor at Princeton University in the Department of Civil and Environmental Engineering where she is the Director of the Architecture and Engineering Program. Her scholarship is in resilient building design and in studies of the best examples of structural designs of the present and past. She has co-authored the book Felix Candela: Engineer, Builder, Structural Artist and has recently launched a MOOC titled "The Art of Structural Engineering: Bridges."

\section{Dr. Aatish Bhatia, Princeton University}

Aatish Bhatia is an Associate Director (Engineering Education) in Princeton University's Council on Science and Technology. He works with faculty in engineering and related disciplines on incorporating active learning in the classroom and bringing science and engineering to a wider audience.

\section{Dr. Evelyn Hanna Laffey, Princeton University}

Dr. Evelyn Hanna Laffey is the Associate Director of the Princeton University Council on Science and Technology. Previously, she served as the Assistant Dean for Engineering Education at the Rutgers University School of Engineering. She has a bachelors degree in mathematics and doctorate in mathematics education from Rutgers University. She has over fifteen years of experience working with K-16 students and educators. She is interested in exploring the intersection of cognition, affect, and identity within STEM education and operationalizing research findings to provide an excellent and equitable education to all students. 


\section{Effective Approaches for Teaching STEM-literacy for All Majors: The Example of Resonance}

\section{Introduction}

STEM education should not be focused solely on producing STEM professionals. Universities educate students who often transition into leadership positions in government, education, civic administration, law and business, with significant influence in society. Thus it is our obligation to graduate students who can question, think, and analyze for themselves, and are scientifically and technically literate. Recognizing this, most universities require non-STEM students to take at least one STEM class.

The American Society for Engineering Education concurs by stating that "Engineering colleges should accept responsibility for providing technical literacy programs to liberal arts students." [1]. And the NAE report, "Educating the Engineer of 2020" [2] states: "It is in the enlightened self-interest of engineering schools to help the public understand what engineers do and the role that engineering plays in ensuring their quality of life. Moreover, a country weak in technological literacy will have increasing difficulty competing in the technology driven global economy of the $21^{\text {st }}$ century. Thus we recommend that the engineering education establishment should participate in a coordinated national effort to promote public understanding of engineering and technology literacy of the public."

At Princeton University, two engineering courses that have been taught for decades to meet this objective of educating all majors about engineering. Each course enrolls on average 125 to 150 students per year, and $75 \%$ or more of those students are not engineering majors. The first introductory course called "Structures and the Urban Environment", begun in 1974, traces the development of structural engineering through case studies of outstanding structures and designers. The course covers a timeline that begins with early iron structures of the industrial revolution and culminates with supertall buildings, long-span bridges, and sustainable designs of the 21 st century. The second introductory course, "Engineering in the Modern World", begun in 1985, centers on the transformation of American society by engineering through studies of the great innovations of the nineteenth and twentieth centuries in the main branches of engineering: civil, mechanical, electrical, chemical.

This paper focuses on the first course, "Structures in the Urban Environment". As a result of both content and effective pedagogical approaches, it has positively changed perceptions about engineering and the societal role of engineers for students from various majors. This paper illustrates effective teaching practices for this introductory course on civil engineering, which have improved attitudes, perceptions, and understanding of engineering. The approach that has been taken to meet the objectives of effective practices, and evaluation is: (1) developing, 
incorporating, and detailed documenting of interactive activities for the lectures; and (2) executing and analyzing student surveys, interviews, focus groups. While the discussions in this paper revolve around a specific course, the approaches are transferrable to other engineering courses taught to liberal arts majors as well.

\section{Overview of Structures Course and Interactive Teaching Methods}

The introductory course "Structures and the Urban Environment" emphasizes that design creativity involves both discipline and play, where 'discipline' is related to quantitative skills and the application of technical knowledge, and 'play' is related to skills such as aesthetic exploration within constraints. Since its inception, this course has been delivered with lectures, labs, and seminars (recitations) to both STEM and non-STEM majors. Until 2014, the lecture portions of the course was delivered largely in a traditional style where the lecturer speaks for 50 minutes without interruption. Most of us would be challenged to hold students' attention for this long, especially in the current technological landscape that offers numerous distractions from personal electronic devices.

Recently, research-based pedagogical techniques were introduced in the lectures and recitations. Research has shown that delivering the course with such techniques (e.g., interactive techniques student-to-student and student-to-faculty) was by far the most important influential positive factor in a student's development. These research-based techniques demonstrate improved student attitudes and led to a higher level of knowledge acquisition (they remembered and comprehended more). [3, 4, 5, 6] Recent calls to action encourage engineering faculty to utilize these research-based techniques. This interactive approach is significant for all teaching, no matter who the audience; but the authors posit that it may be even more significant for teaching liberal arts majors, where the students in this case may not have a solid background in core concepts related to engineering (e.g. physics) and may even have negative affect towards engineering or low self-efficacy (i.e., enter with the attitude of 'I am not sure I can do this'). For example, in the first lecture of the course, using online polling, the instructor asks "What do you expect to be the greatest challenge in this class?". Partial responses are shown in Figure 1, where it is seen that "physics" comes up often, as do other anxieties. Although not shown, "math" is another popular response, as are the laboratory components of the course.

Although math and physics does play a role in the class, this is subordinate to learning what structural engineers 'do' and the design process. They learn that design is a creative process and therefore iterative. Further, they learn that the creative realm must be disciplined by math and physics, but such should not be seen as constraints to design creativity.

As of May 2016, we have modified $85 \%$ of the course lectures to make use of active learning pedagogies, such as interactive lecture demonstrations, hands-on activities, polling questions, and discussion questions. We are continuing to work towards developing further interactive teaching exercises for this course. Previous conference papers by the authors have illustrated 
some examples of effective teaching approaches. For example, [7] discusses some kinesthetic activities, [8] discusses effective practices using online polling, and [9] discusses effective interactive methods for teaching reinforced concrete. This paper specifically focuses on interactive lecture demonstrations (not just 'plain' lecture demonstrations). An example of such a demonstration is provided to teach concepts of resonance in buildings for earthquake performance. What makes this discussion innovative is that it illustrates an effective approach for teaching a fundamental concept (such as resonance) as applied to engineering design (seismic resistance of buildings) in a manner that is effective for students of all majors. The evaluation of the impact of the course on students' content knowledge and attitudes towards engineering support similar findings that demonstrate the efficacy of utilizing evidence-based teaching practices and case studies.

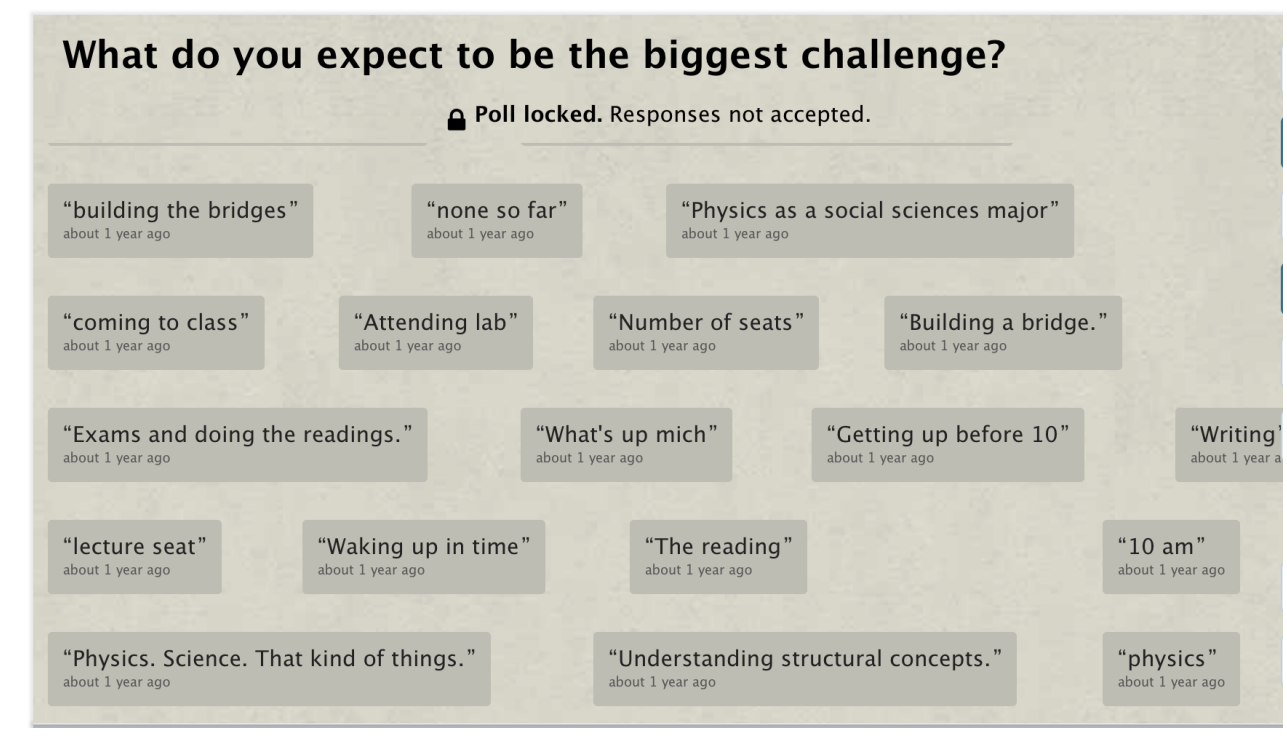

Figure 1. Student responses to their perception of greatest challenge.

\section{Resonance Resonates: Predict, Experience, Reflect}

An effective approach for implementing an interactive lecture demonstration involves three stages: predict, experience, and reflect [10]. This Section defines each stage and how it was executed in a lecture with the objective of teaching students about resonance in buildings during an earthquake.

\section{Predict}

In a study by Crouch et al. [11], it is shown that students who just passively observe a demonstration do not have a better understanding of the subject than students who do not observe the demonstration at all. However, involving students by asking them to predict the outcome of the presentation yields a better understanding. With this concept in mind, students were asked to predict which "building" would sway the most in an "earthquake" (see Figure 2). The word "building" is in quotes because it is represented by a wooden block on top of a 
threaded rod. Four blocks of the same size are each attached on top of 4 threaded rods of different heights. This teaching tool is called the Building Oscillation Seismic Simulation (BOSS) model, a pedagogical physical demonstration developed by the American Geophysical Union and revised by the Incorporated Research Institutions for Seismology (IRIS) consortium [12]. Since the blocks are all the same weight, the only difference between the four "buildings" is the stiffness, as represented by the heights. All four "buildings" are placed on a two-by-four, which is mounted on a set of wheels.
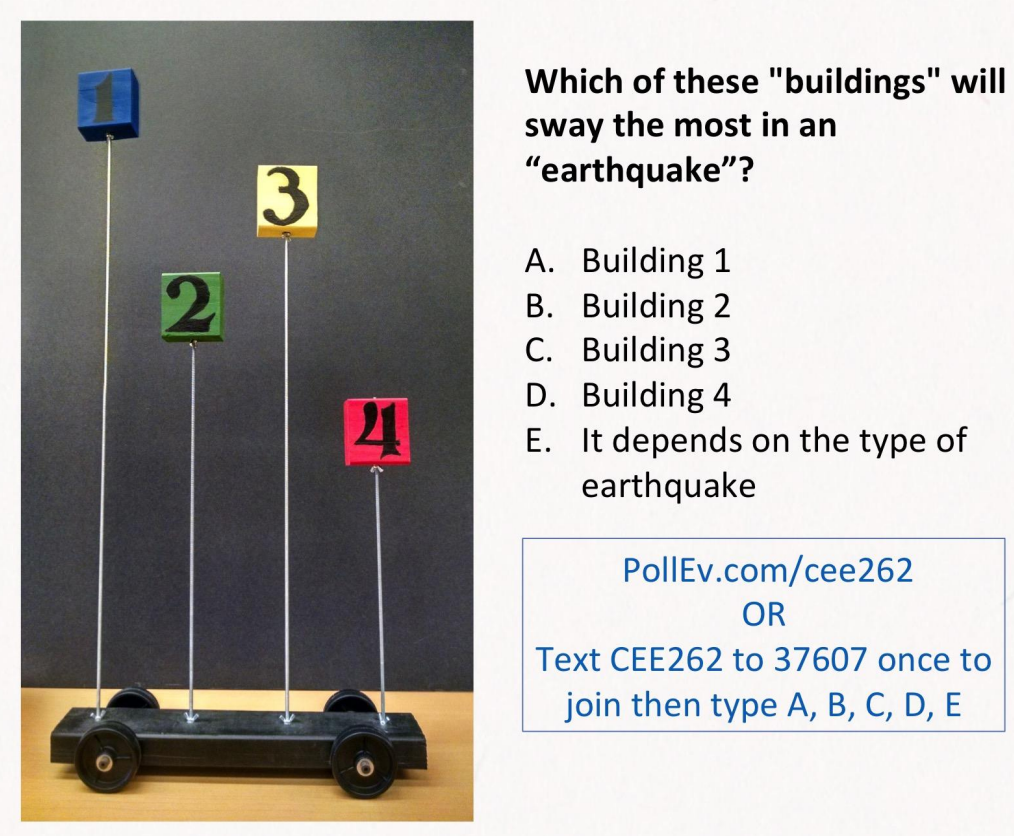

A. Building 1

B. Building 2

C. Building 3

D. Building 4

E. It depends on the type of earthquake

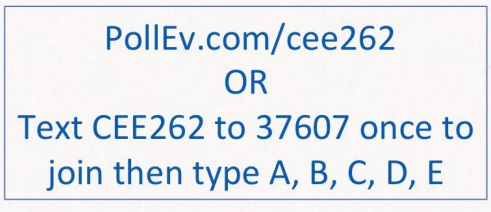

Figure 2. Predict: Students are asked to predict the outcome.

Students are asked to predict which buildings will sway the most in an "earthquake", where the earthquake is simulated by the instructor by oscillating the two-by-four base on wheels. The prediction is done by online polling, where students can observe the class results. In the two years (2015 and 2016) that this interactive demonstration was done, the results were similar to that shown in Figure3. 


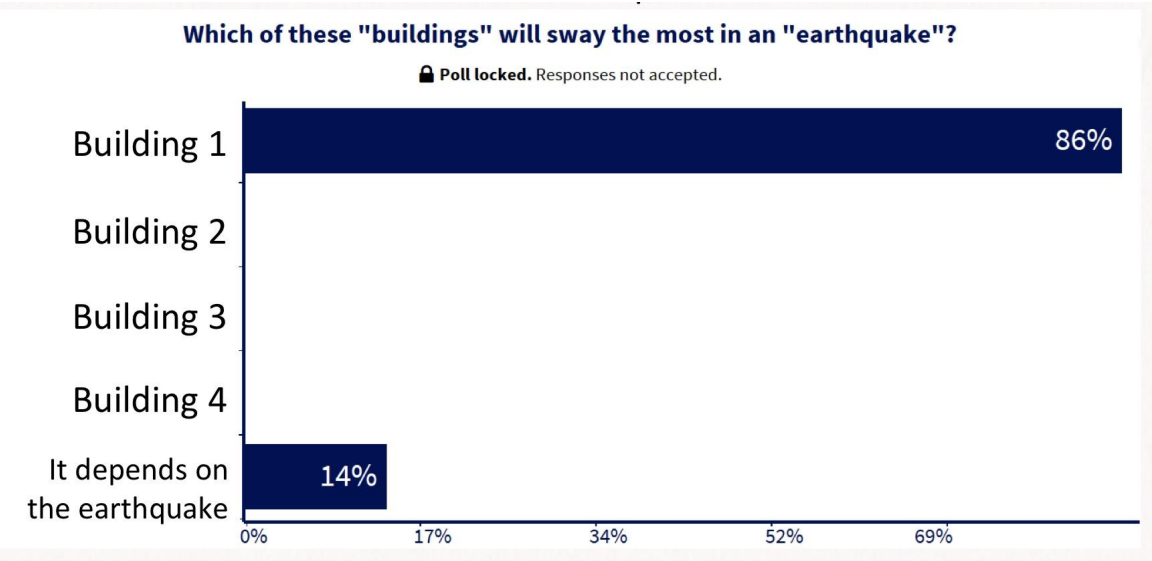

Figure 3. Predict: Students' online prediction of the demonstration. (2015 poll shown).

With Figure 3 projecting on the screen, the instructor then shakes the base with a frequency to excite Building 4 (or 3 or 2 ), which no one selected. The response of the students is literally an audible 'gasp' as students express their surprise at the outcome. Shaking the model to excite the frequency of Building 4 is the most dramatic, as it is the shortest building and most students predicted that the tallest building would move the most. The literature shows that learning by being surprised (disconfirmation) is very effective [13], as such 'discrepant events' highlight a mismatch between students' observations and their prior expectations, and therefore generate interest. To further the demonstration, the instructor shakes the base to excite Buildings 1,2, and 3 , one at a time. It is unknown how long a student will remember this concept; however, at the end of the semester in response to the question 'Name one thing that you will never forget' once student responded: "I will never forget the idea of resonance in skyscrapers... because of the wonderful demo... It was amazing watching different blocks move with different frequencies... (seemed like magic!)."

With their attention and curiosity captured, one can then present the equation and physics behind the "magic". Figure 4 shows the slide that follows the interactive demonstration with the relevant equation. It can thus be explained that 'resonance' happens when the natural period of vibration of the building, which is calculated with the equation shown, matches the frequency of ground shaking. The next step is for them to experience resonance on their own. 


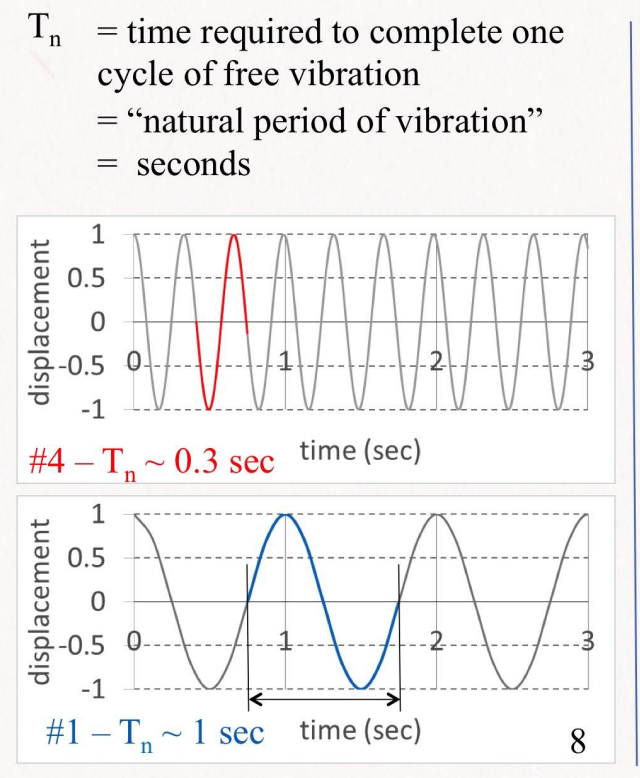

$$
\begin{aligned}
& \mathrm{T}_{\mathrm{n}}=2 \pi \sqrt{\mathrm{m} / \mathrm{k}} \\
& k=\text { stiffness } \\
& m=\text { mass }
\end{aligned}
$$

The only difference between the "buildings" in this example is $k$.

$\mathrm{k}$ for \#1 is smaller, therefore $T_{n}$ is larger

Figure 4. The physics behind the demonstration.

\section{Experience}

The course in which this interactive demonstration happens enrolls on the order of 150 students. All of these students can easily experience resonance in their seats (i.e., there is no need to go to a lab) with two pieces of mini marshmallows and two pieces of spaghetti. As shown in Figure 5, the marshmallows are placed on top of the spaghetti, and the spaghetti are held in the hands with two different heights. The student then shakes his/her hand until it resonates with one spaghetti/marshmallow "building". Then the hands shake at a different frequency until the other spaghetti/marshmallow "building" resonates. 


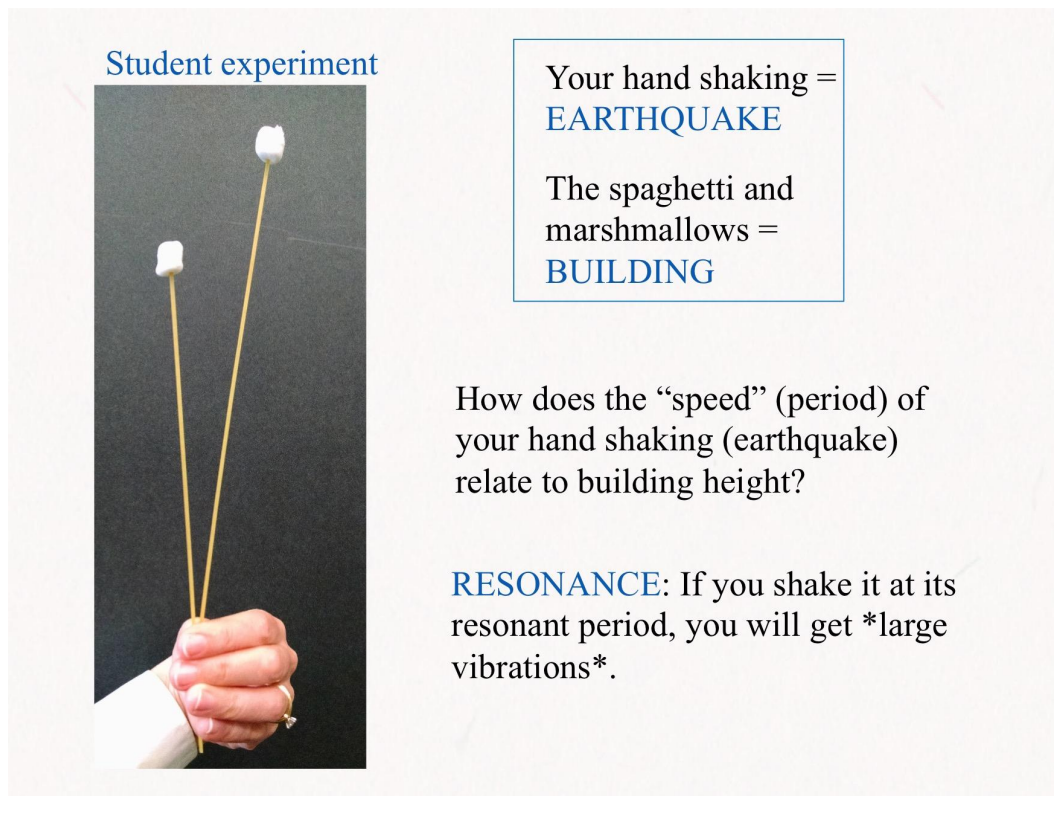

Figure 5. Experience: Resonance with spaghetti and marshmallows.

\section{Reflect}

In the reflection step, students are presented with a prompt that asks them to apply their understanding in a novel context. Opportunities for reflection help students apply newly-gained knowledge and consolidate their understanding [4].

In the reflect phase of the interactive demonstration a case study is presented: the 1985 Mexico City earthquake. Figure 6 shows the slide used in the class, which asks students to reflect on why most buildings that collapsed during the Mexico City earthquake were between 5 and 15 stories. Once again, online polling is used but this time as an open-ended question instead of multiple choice. The example of 2015 responses is presented in Figure 7 (2016 responses are similar).

It is seen in Figure 7 that most students appear to have connected the interactive demonstrations of resonance to a real-world application. They understood that the ground motion period of the Mexico City earthquake was similar to the natural period of vibration of the 5 to 15 story buildings.

Consider that the large majority of the students responding are not engineering students; and consider the anxieties that are partially demonstrated in Figure 1. In less than half-hour these students were able to understand resonance in tall buildings. 
Case study: "The event caused between three and four billion

Mexico City USD in damage as 412 buildings collapsed and

Earthquake another 3,124 were seriously damaged in the city."
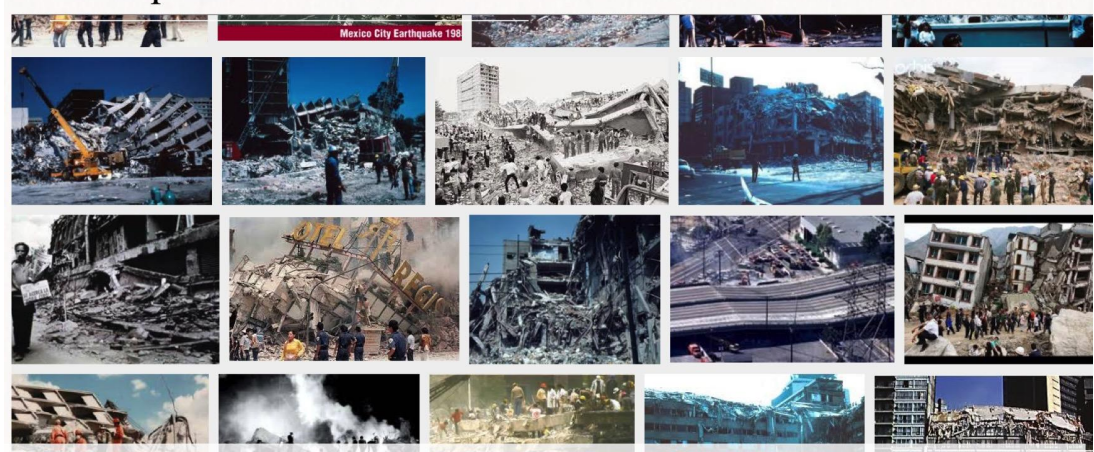

Most affected buildings of intermediate height - between 5 and 15 stories... WHY??

PollEv.com/cee262 - OR -

Text CEE262 to 37607 once to join then type response

Figure 6. Reflect: Using a case study students apply their knowledge to answer a question.

\section{Why were most affected buildings of intermediate height - between 5 and 15 stories?}

\section{O Poll locked. Responses not accepted.}

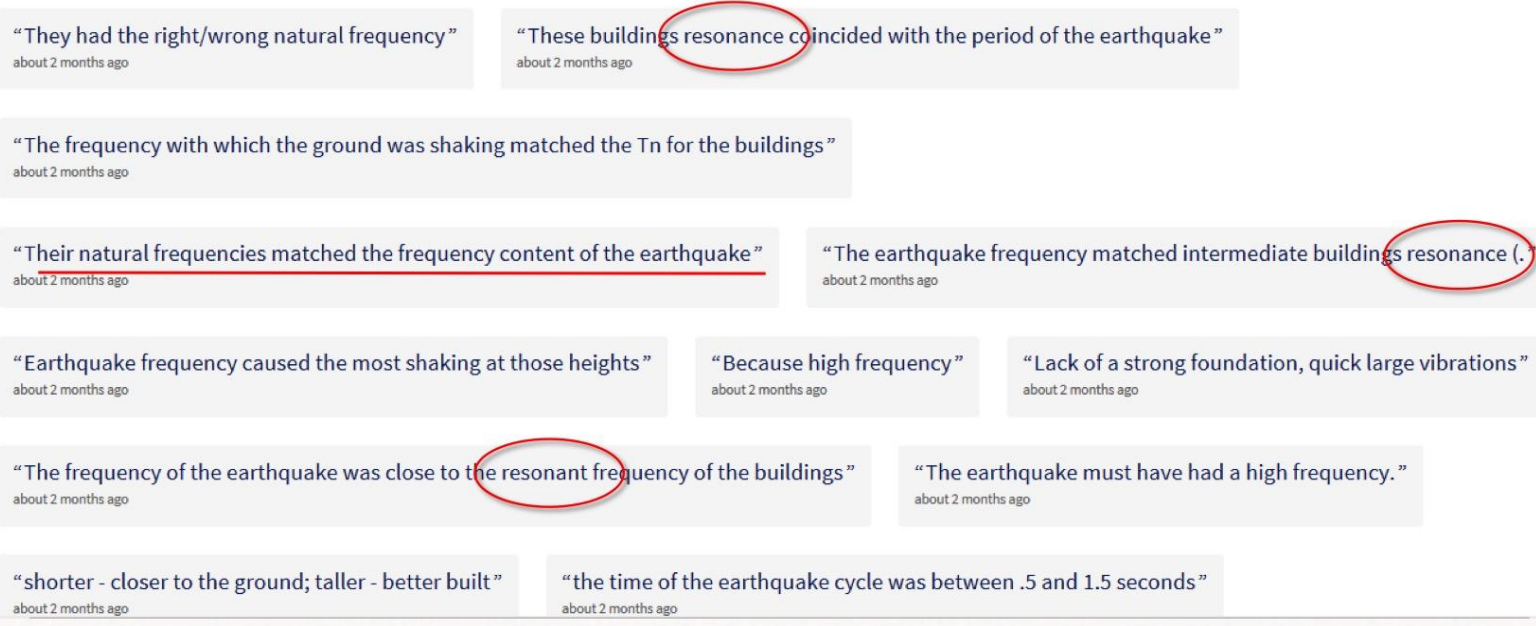

"the time of the earthquake cycle was between .5 and 1.5 seconds" about 2 months ago

Figure 7. Reflect: Open-ended online polling response to 'reflect' question.

\section{Learning Outcomes}

We adapted the Student Assessment of Their Learning Gains (SALG) survey [14] in order to measure the students' self-reported gains in their skills, understanding of the course content, attitudes towards engineering, as well as gains due to various course components (e.g. assigned readings, lectures, hands-on activities). The survey was administered by one of the Co-PIs on the grant. To reduce potential bias, the survey was administered by one of the Co-PIs who was not a 
member of the teaching team. The enrolled students met her only via email and in-person near the end of the course. She only discussed the survey and assured the students that their participation would not impact the students' course grades. Partial results of this survey are presented in Figures 8 and 9, which are for 2016. These results are slightly improved from 2015 (where $n=65$ ). Note that no data is available for comparison of learning assessment prior to adopting the techniques discussed in this paper. Furthermore, effective Spring 2017, we are administering a pre- and post-survey to assess change in students' cognition and attitudes over the course of the semester.

In $2016,100 \%$ of the students $(n=21)$ reported great, good, or moderate learning gains due to the lecture demonstrations. Furthermore, a large majority of students reported great, good, or moderate learning gains from the hands-on activities (95\%), interacting with peers in class $(91 \%)$, polling questions $(81 \%)$, and participating in group work $(72 \%)$. In addition, when reporting on their attitudes towards engineering, $100 \%$ of students $(\mathrm{N}=21)$ reported good, great or moderate gains in seeing engineering as a creative profession, enthusiasm for the subject, interest in discussing the subject area with friends or family, and in possessing an aesthetic and technical appreciation for bridges, towers, shells, and other structures. These results serve to highlight the efficacy of the interactive teaching methods adopted in this project towards improving student learning outcomes as well as attitudes towards engineering. Further details about our evaluation methods and results can be found in the ASEE 2016 conference paper entitled 'Enhancing Student Cognition and Affect through the Creative Art of Structural and Civil Engineering' [15].

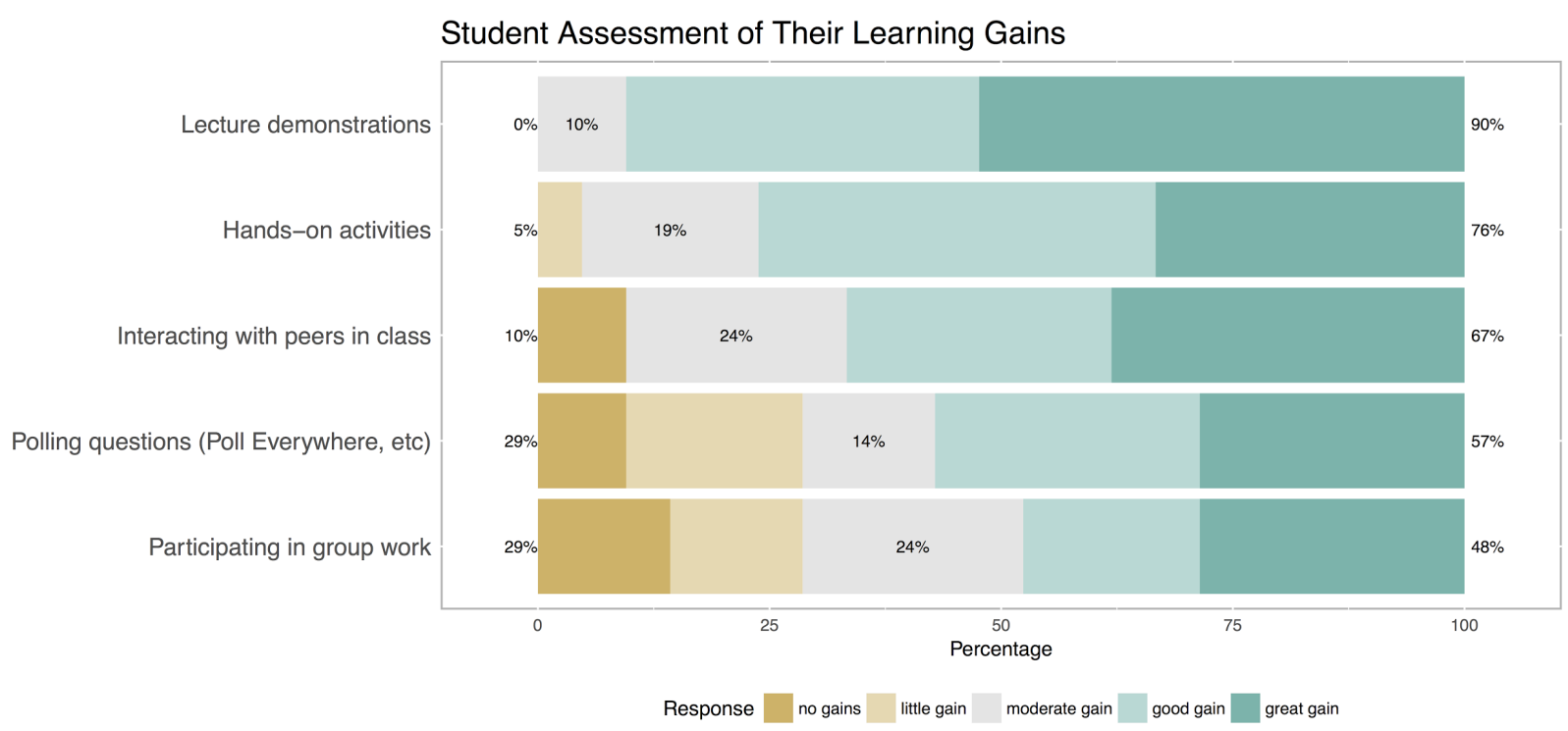

Figure 8: Survey results pertaining to interactive teaching methods (2016 results shown) 


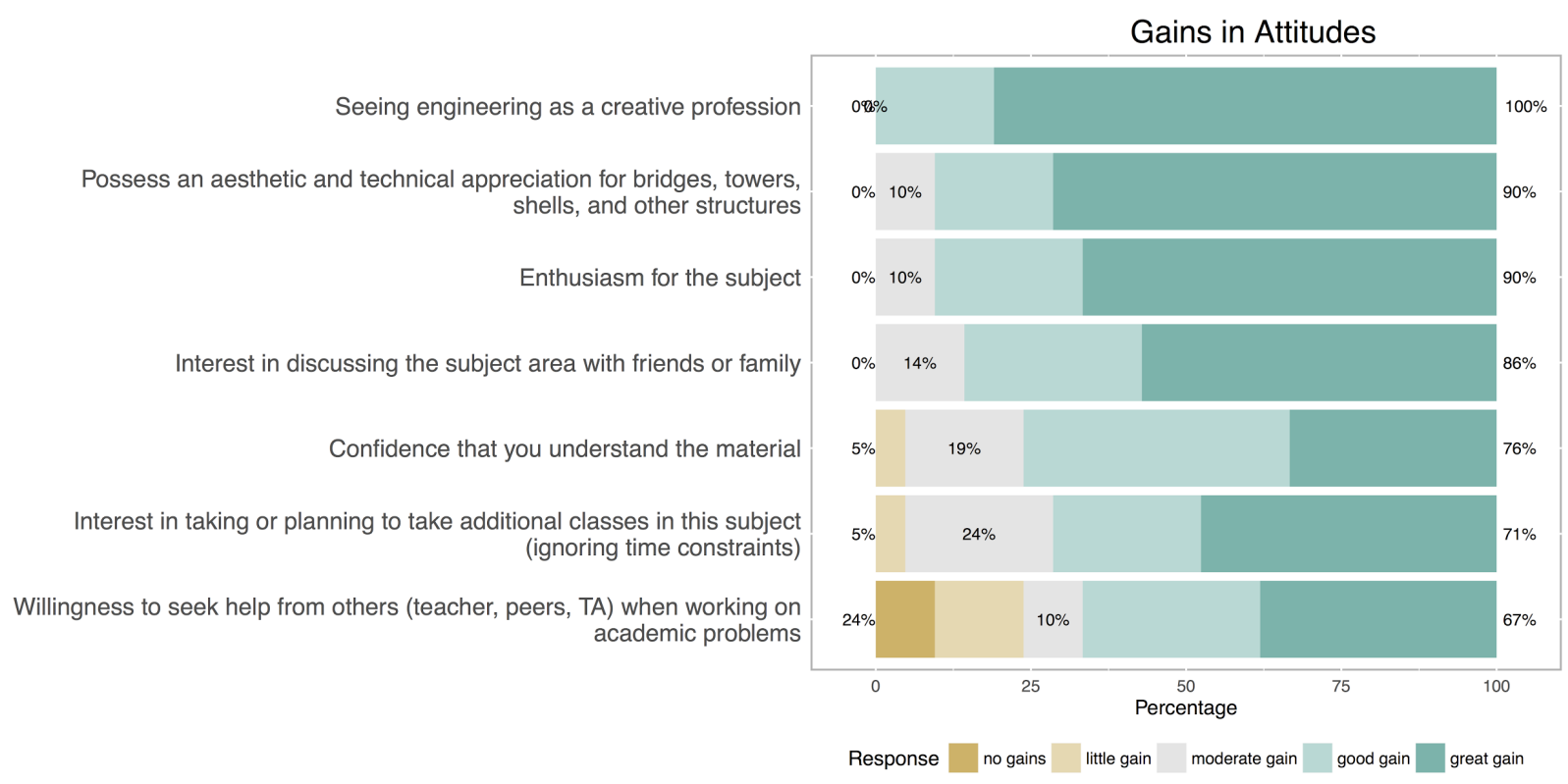

Figure 9: Survey results pertaining to gains in student attitudes (2016 results shown)

\section{Conclusions}

A course that teaches engineering to all majors has recently been enhanced with active learning pedagogies, such as interactive lecture demonstrations, hands-on activities, polling questions, and discussion questions. This paper presented, specifically, the teaching of resonance in tall buildings with these learning pedagogies. Since students that are not majoring in engineering may experience more negative affect towards engineering or lower self-efficacy for an engineering course, these active learning exercises have the potential to be very effective in leveling the playing field. In the example of the course presented in this paper, survey results show great gains in learning as enabled by active learning, and great gains in attitude (e.g., enthusiasm for the subject).

\section{Acknowledgements}

This material is based upon work supported by the National Science Foundation under Grant no.: 1432426. Any opinions, findings, and conclusions or recommendations expressed in this material are those of the author(s) and do not necessarily reflect the views of the National Science Foundation.

\section{References}

[1] ASEE (2012). "The Green Report - Engineering Education for a Changing World", American Society for Engineering Education. https://www.asee.org/papers-andpublications/publications/The-Green-Report.pdf 
[2] NAE (2005). Educating the Engineer of 2020: Adapting Engineering Education to the New Century (2005) National Academy of Engineering of The National Academies, The National Academies Press, Washington, DC

[3] Astin, A., What Matters in College? Four Critical Years Revisited, San Francisco, Cal.: Jossey-Bass, 1993.

[4] Bransford, J.D., Brown, A.L., Cocking, R.R. (2000). How People Learn, Brain, Mind Experience, and School. Committee on Developments in the Science of Learning, Commission on Behavioral and Social Sciences and Education, National Research Council, National Academies Press, Washington D.C.

[5] Light, R.J., The Harvard Assessment Seminars: Second Report, Cambridge, Mass.: Harvard University, 1992.

[6] Smith, K.A., Sheppard, S.D., Johnson, D.W., Johnson, R. (2005). "Pedagogies of Engagement: Classroom-based Practices", Journal of Engineering Education, January.

[7] Bhatia A., Chen P., Perez K., Laffey E., Garlock M. (2015). “Active Learning Pedagogies Promoting the Art of Structural and Civil Engineering” Presented at 2015 ASEE Annual Conference and Exposition, Seattle, WA

[8] Bhatia, A. Laffey, E., Garlock, M.E.M. (2016). "Engaging Students with the Creative Art of Civil Engineering", Proceedings of the 2015 ASEE Annual Conference, New Orleans, LA, June 27-29.

[9] Garlock, Maria E. Moreyra, Aatish Bhatia, and Negar Elhami-Khorasani. "Introducing Modern Teaching into a Classic Course on Structural Art." IABSE Symposium Report, 105:1-2. International Association for Bridge and Structural Engineering, 2015.

[10] Interactive Lecture Demonstrations. Dorothy Merritts, Robert Walter, Bob MacKay, Mark Maier, Rochelle Ruffer, Sue Stockly and Ronald Thornton. Accessed Feb 7, 2017. http://serc.carleton.edu/introgeo/demonstrations/index.html

[11] Crouch, C., Fagen, A. P., Callan, J. P. \& Mazur, E. Classroom demonstrations: Learning tools or entertainment? Am. J. Phys. 72, 835-838 (2004).

[12] IRIS, "The BOSS Model:Building Oscillation Seismic Simulation" https://www.iris.edu/hq/files/programs/education_and_outreach/lessons_and_resources/docs/Ori ginalBOSSModel.pdf

[13] NAE (2005). How Students Learn (2005) National Academy of Engineering of The National Academies, The National Academies Press, Washington, DC 
[14] “SALG - Student Assessment of Their Learning Gains.” Accessed May 2, 2016. http://www.salgsite.org/

[15] Laffey, Evelyn H., Maria E. M. Garlock, and Aatish Bhatia. "Enhancing Student Cognition and Affect through the Creative Art of Structural and Civil Engineering" ASEE Annual Conference and Exposition, 2016. 